\title{
Germanica
}

GERMANICA $7 \mid 1990$

Grenze und Entgrenzung

\section{Das Augenlicht der Ferne}

Alfred Kern

\section{OpenEdition}

Journals

Édition électronique

URL : http://journals.openedition.org/germanica/2511

DOI : 10.4000/germanica. 2511

ISSN : 2107-0784

\section{Éditeur}

Université de Lille

\section{Édition imprimée}

Date de publication : 30 juin 1990

Pagination : 151-156

ISSN : 0984-2632

\section{Référence électronique}

Alfred Kern, «Das Augenlicht der Ferne », Germanica [Online], 7 | 1990, Online erschienen am: 18 Juli

2014, abgerufen am 06 Oktober 2020. URL : http://journals.openedition.org/germanica/2511 ; DOI https://doi.org/10.4000/germanica.2511

Ce document a été généré automatiquement le 6 octobre 2020.

() Tous droits réservés 


\title{
Das Augenlicht der Ferne
}

\author{
Alfred Kern
}

Persona: Innerlichkeit und Aussage, unter dem Aufwand und dem Schwund deiner Selbst, die fliefzende Grenze einer Sprache. Dein Schweigen

birgt die Einsicht in die Worte. Neugierde verspricht Helligkeit, Furcht oder Freude. Der Zweifel reicht, wie ein kommender Tag, bis in die Mitte der Welt. Heimische, auch fremde Laute: dein Atem ist Körper, ist Wechsel, ist Dasein, Verlust oder Ausgleich. (A.K.)

1 Literatur bringt uns in die sprachliche Nähe und Wärme einer durch viele Ortsnamen gekennzeichneten Landschaft. Sie ist ein Stück Erde, auf der wiederum der Eigenname der Leute, die Mundart, eine individuelle Schreibart jene ausschließliche Rolle spielt, die wir, teils physiognomisch, als Ausdruck und Körpersprache, teils über das Gehör, als etwas allgemein Vernehmbares zu verstehen haben. Es handelt sich weder um reine Logik noch um eine abstrakte Zeichenoder Datenkunde, sondern um ein konkret sinnliches Eigentum. Es geht um das Wesen und Ansehen einer Person, einer Gesellschaft, einer an Wasser, Erdfläche und Luft gebundenen Gegenwart. Manchem fallt es schwer, vom angekreideten Ich ausgehend, über die eigene Haut bis zum Schattenbild zu kommen, worunter ein noch fremdes Wissen uns erwartet. Sinn und Form liegen so eng verbunden, daß wir bereits, unter der Schwelle des Gesagten, und darüber hinaus, die wunde Stelle oder die wundersamen Mittel suchen die als Teile eine Ganzheit erhellen, sie in ihrer Vielfalt und Verschiedenheit begreifen. Es geht bereits, am Ort der Wahrnehmung, um das Jenseits der Sprache, um die kritisch-bildhafte Kunde einer auf die Wirklichkeit und die Einbildung bezogenen Metapher.

Die Sprache zieht phonetisch an unseren Augen vorbei: Grenzen fallen, oder kommen in Fluß, zum Wechsel und Austausch. Selbst die fremde, noch unverstandene Sprache wirkt, wie die Lust oder Unlust am Andern teilzuhaben, ansteckend. Im kritischen Bewußtsein sind wir zugleich der Betroffene und der Kläger; Ausdruck und Vorstellung stimmen überein, oder fordern weitere, neue Formen. Die Metapher sichert der Sprache keinen endgültigen Bestand. Wir können nur weiter suchen, alte und neue 
Muster vergleichen, sie austauschen oder ersetzen. Das Beispiel ist die übersehbare Größe, die wir, sei es Aufschluß oder Tarnung, Trug, Scherz oder Vorwand, gegen ein neues Kleid eintauschen. Auffallend oder diskret sind wir mimisch anwesend, modisch gesinnt, geistig frei, zugleich ausgesetzt und begrenzt. Ein Mensch trägt nicht, wie der Tiger oder der Löwe, ein Leben lang das gleiche Fell. Er fühlt sich nackt, dem Zweifel ausgesetzt. Er begibt sich in das Wissen der Sitte und der Sprache, ohne Unschuld, mit der Sucht, die Ungewißheit in Kunst, Politik, Kultur aufzulösen. Er stellt sich eine Welt vor, in der, vom Nichts bedroht, Haut, Sprache und Körper, Luft und Atem einund auskommen. Es ist die Frische oder die Müdigkeit einer Stimme. Der Raum, wie die Logik, versprechen reale oder abstrakte Freiheit, Körperbewegung, Tanz oder Probe, ein Stück Ungewißheit wird zum Exempel. Geltung oder Risiko: die Sprache beschränkt sich auf ihren Ort oder schwemmt die Gegenwart fort. Kommt sie gut an, so schafft sie, in ihrer Strenge, im aufgelockerten Raum, eine begrenzte Ordnung, reiht sie ein, in eine noch unfertige Welt: Auf der Suche ihrer selbst, ist die Geschichte wie das Leben, Bildung. Die manchmal vollendete Form wird abgestoßen, ohne Nachfolge, ohne die erfinderische Not. Vielfalt oder Mangel: es ist eine Frage der Grenze.

Als Grenzgänger, hier, im rheinischen Raum, lebe ich unter verschiedenen Sprachen, auch wenn ich sie nicht, oder kaum beherrsche. Der fremde Klang gemahnt mich an die hoffende Sprachlosigkeit der Kinder vor dem Muster einer noch unerschlossenen Welt. Das ist eine Art, spielend frei zu sein. Nach der Arbeit kommt das Straßenleben mit den vielen Anregungen, Kino, Musik, Bilderbücher. Sie trugen, früher, jenseits der flimmernden Grenze, ihre Aura, unter der ich, später, Geographie, Literatur, Völkerkunde und Kunstgeschichte entdeckte.

Heute noch bin ich irgendwie sprachlos vor einer Welt, die mir wie ein offenes Buch vorschwebt. Schreibbereit und bereits verschrieben, finde ich die wahren Lichter und die eigenen Bilder so auffallend verwandt, daß ich mich zugleich mächtig und ohnmächtig fühle. Die Stimmung geht der Stimme voraus, wie die erste Zeile im Buch. Ich muß mich einer verschiebbaren Lust unterstellen, mich, ungebändigt, der Vernunft aussetzen, um das treffende Wort zu finden, das der Sprache widerstehend, dem Zwang der Sinne treu bleibt, sie verdichtet wie die vorüberziehende Wolke am blauen Himmel der Sucht. Die Sprache erläutert und verdunkelt ihren Fluß. Sie ist Vorgefühl, Neubildung, Anwesenheit anderer Sprachen. Das Auge sieht besser und viel mehr als das innere Gehör: doch das Geschriebene wird zum Maß der Zeitrechnung, einer Sicht, die dem Atem weiterhilft, Haut und Körper zu lichten, sie zu Papier zu bringen, wie eine sekundäre Haut. Das Anführungszeichen ist doppeldeutig, wie die musikalische Partitur, in der Schwebe zwischen dem Tod und der Gewißheit, ein sinnvolles Vergehen. Dank der Bilderwelt und des durchlässigen Raums, entgehen wir der neurotischen Logik der reinen Vernunft, einer abstrakten Gewißheit, die uns zahlenmäßig totschweigt oder der geschichtslosen Verflachung aussetzt.

Die Allegegenwart der Medien droht uns um unsere eigene Zeit zu bringen. Doch kann ich mich als Einzelfall schriftlich, das heißt sprachlich, behaupten. Die Allgemeinheit bleibt zugleich logisch und geographisch erhalten in dem offenen Raum, der mich begrenzt und befreit. Ich stelle mich gegen die Medien, gegen den eigenen Verstand, um ihnen das dichte und durchsichtige Wort abzuringen, das mich zwischen dem Schweigen und der Hellsicht zu weiterem Vergleich führt, mich im Halbdunkel bedrohend und vielversprechend über die eigene Grenze führt. 
6 So kann ich mich, todernst und spielend leicht, auf verschiedene Sprachen, auf verschiedene Gattungen oder literarische Vorbilder berufen. Auf die alemanische Mundart, vorerst auf das Kirchenlatein, schließlich auf die deutsche und die französische Schriftspräche. Die Mundart: ich stand auf ihr, wie auf den Beinen, im Umgang und Habitus, da ich das Gefühl bewahrt habe, anonym, und doch selbstverständlich derselbe geblieben zu sein: der Straßenjunge, der, von Haus zu Haus, die Nachbarn unter einen selben Himmel bringt, ohne endgültigen Bescheid, ohne endgültige Absage. Eine Frage stellt sich mit der Antwort auf eine andre Frage um, oder eine andere Sprache. Kleider machen Leute. Aber l'habit ne fait pas le moine.

7 Eine nie abgeschlossene Gewissenserforschung: so kommt mir Literatur vor, auch die Ironie der vielen Möglichkeiten der Sprache am Eingang und Ausgang des kritischen Nährstoffes den wir verarbeiten, verwandeln und ausscheiden. Haut, Haltung und Gebärde sind manchmal ohne Worte eine simple Art, Anschluß zu suchen, lärmend einen Weg zu finden, und auch wieder zusammen zu sein. Ich denke oft an das Kartenspiel der Nachbarn im Hof, an ihre Körpernähe und Freiheit beim Spiel: As, Trumpf, König oder Dame, kein Bauer verschrieb sich endgültig einer Obrigkeit, der oppressiven Allgegenwart der Gesellschaft und der Medien.

Die Schriftsprache widersteht der Normalisierung: sie bildet ihre eigene Zeit, ihren eigenen Raum. Sie verwandelt die Sprachgrenze wie das Kleid, das sich mit dem Sprachkörper abfindet, als Stoff der Haut anliegt, als Muster austauschbar bleibt, von demselben Autor getragen, wohl verschieden und doch wie der Name und das Schild der persönlichen Signatur untersteht.

9 Es handelt sich nie darum, eine Sprache, zu übersetzen, sondern sich in ihr recht oder wohl zu fühlen, wie in einem Anzug. Meine Liebe zur französischen Sprache haftet an der glatten, sehbaren Fläche eines Grundstoffes, gut angemessen im Schnitt, zugleich leicht und tragbar.

10 La sublime étendue - die Haut - erinnert mich an Descartes, an einen Zweifel, der auf der Haut liegend, zugleich Abenteuer und Einkehr verspricht. Eine Art décalcomanie im Gemach des Schriftstellers, der manisch schreibt oder zeichnet, dem Körper und dem Gewissen auf der Spur ist, bis zum hellen Blatt, dem schwarzen Zeichen der Graphik. La Carte $d u$ Tendre wenn er parodistisch sein Eigen auf der Landkarte sucht. Haut und Sprache, oder der Bilderbogen unter der Form eines Buches, oder das besinnliche Schweigen, das dem Schreiben vorausgeht: ein Gedicht wird in der Schwebe niedergeschrieben wie zu einem Abschied.

11 Der deutschen Syntax verdanke ich den Raum, das sprachliche Gefühl, das miéh trägt, auch wenn ich Französisch schreibe, und mich als solcher in einen noch stummen Raum versetze, worin das Bild, die Einbildung, die wahre Begebenheit dem Auge den Vorrang über das Gehör geben, es auf eine Sprache abstimmen.

12 Die deutsche Syntax ist als solche eine «Veranschaulichung» getragen durch das Zeigen am Phantasma, die wiederholte Orientierung am betonten Duktus der Aussage. Sie verfügt über ein Vorfeld und eine Ordnung der Akzente, die sie neutralisieren kann, die als solche immer wieder dem Sprecher den Vorrang gibt über das geschriebene Wort. Der Körper bleibt haptisch anwesend im Ausdruck so wie unter der Vorstellung einer engen und nahen, dann einer breiten, großen Welt. Die Mundart widersteht im deutschen Sprachraum, besser als anderswo, der Schrift-oder Beamtensprache und es ist wohl die Bühnensprache, die, episch oder lyrisch, betont oder verharmlost über 
Funk, Politik und Bildschirm den begrenzten Raum einer Landschaft, die Gemeinde als besondere Freiheit, als lokaler Widerstand dem allgemeinen Geschehen entgegengestellt. Mit vielem Ernst kommt der Philosoph zu einem Gedankensystem über Phénoménologie und Sprache, da wo der Franzose oft kritisch scherzend mit den Worten spielt.

Das ausschlaggebende, in meinem Fall, scheint mir ein Mangel oder Unvermögen zu sein. Ich habe ein sehr schlechtes Wortgedächtnis, wenn es um die Wiederholung einer bereits vorhandenen Fassung der Sprache geht. Ich bin gebunden an Körper und Raum, im Vorgefühl der Worte, die ich suche, um ein Wissen wieder zu beleben. Es macht mich hellsüchtig in dem eigenen Rum auf dem dunklen Körpergrund worunter ich viel Erlebtes gelagert habe, viele Begegnungen, Reise-oder Leseeindrücke, ohne daß ich auch nur einen Satz aus einem gelesenen Buch zitieren könnte.

Ich verfüge nur über einige Klangmeldungen aus den allerersten, tief greifenden Erschütterungen, die mich in die Nähe einer dunkel gewünschten, hell erleuchteten Vorlage brachten. Das Schreiben zieht mich aus der Verlegenheit, aus einer Unruhe, aus einer Stimmung, die ich beide bildhaft und sprachlich zu meistern habe, etwa so wie das Stimmen der Instrumente vor dem Angriff, dem ersten Satz der Muskinstrumente. Das Kind, die Klage oder Laudatio, ein kommendes Rezitativ oder eine prachtvolle Umgebung, die mich zwischen Dunkelheit und Licht, zwischen Bibel und Alltag unter das nun bestimmende Musterbild setzen. Vom deutschen Raum kamen so Mozart und Goethe, Papagenos Flöte und Leierkasten, Fausts Gretchentragödie: Meine Ruhe ist hin, ich finde sie nimmer und nimmer mehr... Ich hatte nur einen dunklen Schlußsatz behalten und gelesen, Das ewig weibliche zieht uns hinan. Eine gute oder schlechte Ahnung, und mit dem Anfang: Die Sonne tönt nach alter Weise, in Bruder Sphaeren Wettgesang. Und dann komme ich wieder zu Nietzsche: Du Mistralwind, Wolkenjäger oder zu Ringelnatz Fisches Nachtgesang.

Im Französischen ist es die Genealogie eines Wortes, die mich durchgreifend weiter bringt: rosa, rosae, rosam, ausgehend vom Lied, das meine Mutter gesungen, am Klavier begleitet hatte: Es ist eine Ros' entsprungen, aus einer Wurzel zart. Unter dem Geflecht der Sinne verfalge ich meine eigentliche Sprache: Et rose, elle a vécu ce que vivent les roses, l'espace d'un matin.

Ich war dreizehn Jahre alt. Mir ging die Liebe zur französischen Sprache auf. Seitdem habe ich Lust am Schreiben, Freude am Geschlecht, am unfertigen Werk der Sprachen.

\section{AUTEUR}

\section{ALFRED KERN}

Prix Renaudot 1960 